\title{
Comparison of blood pressure levels among four age groups of Chinese children matched by height
}

\author{
Z Wang ${ }^{1}, \mathrm{~J} \mathrm{Ma}^{2}$, B Dong ${ }^{2}$, Y Song ${ }^{2}, \mathrm{PJ} \mathrm{Hu}{ }^{2}$ and B Zhang ${ }^{2}$ \\ ${ }^{1}$ Centre for Chronic Disease, School of Medicine, the University of Queensland, Queensland, Australia and \\ ${ }^{2}$ Institute of Child and Adolescent Health, School of Public Health, Peking University Health Sciences Center, \\ Beijing, China
}

\begin{abstract}
Hypertension in children is frequently undiagnosed. Normal blood pressure is currently defined as a function of two continuous variables, age and height for each gender. Applying the current cutoff values to assess a child's blood pressure is time consuming. To separate the independent effect of age from that of height on blood pressure, we conducted a multiple group matched study to investigate if blood pressure levels in children with a given height distribution vary with age. An equal number of 2539 Chinese children from each of the four age groups $(7,8,9$ and 10 years) were individually matched by height, sex and geographic region. We used the matching technique to force the four age groups to
\end{abstract}

Keywords: children; blood pressure; normal percentiles

\section{Introduction}

With the epidemic increase in childhood overweight problems in both developed ${ }^{1,2}$ and developing countries, ${ }^{3,4}$ increased attention to weight-related health problems including hypertension is warranted. ${ }^{5,6}$ However, hypertension in children and adolescents are frequently undiagnosed. ${ }^{7}$ One of the primary factors accountable for the low diagnosis rate is the lack of knowledge of normal blood pressure values by clinicians. ${ }^{7}$ The current consensus guidelines define normal blood pressure in children as a function of age and height for each gender. ${ }^{8-10}$ Because the normal blood pressure values are considered to vary according to two continuous variables, age and height, simultaneously, it is cumbersome for clinicians to identify children with elevated blood pressure. ${ }^{7}$ Previous

Correspondence: Dr Z Wang, School of Medicine, University of Queensland, Royal Brisbane \& Women's Hospital, 817 Health Sciences Building, Herston, Queensland 4029, Australia.

E-mail: z.wang@uq.edu.au or Professor J Ma, Institute of Child and Adolescent Health, Peking University Health Sciences Center, 38 Xueyuan Road, Haidian District, Beijing 100191, China.

E-mail: majunt@bjmu.edu.cn

Received 13 January 2011; revised 3 March 2011; accepted 18 March 2011; published online 12 May 2011 have an identical height distribution. Systolic and diastolic blood pressures significantly increased with increasing age before matching. After matching, four groups had strikingly similar levels of blood pressures, and the differences among four groups were small and not statistically significant. Once height is taken into consideration, age has little impact on blood pressure. Our findings, if confirmed in children of other ages, suggest that blood pressure percentile charts can be considerably simplified by establishing normal percentiles according to height alone for each gender.

Journal of Human Hypertension (2012) 26, 437-442; doi:10.1038/jhh.2011.45; published online 12 May 2011

studies have indicated that the consideration of age alone is inadequate to gauge a child's blood pressure, ${ }^{9-12}$ therefore, the normal blood pressure values have been established according to age and height simultaneously. The most powerful determinant of normal blood pressure in children is maturation. ${ }^{11,12}$ Height as an easily measured indicator of physiological maturity is related to blood pressure independent of age. ${ }^{11}$ Height and age are highly correlated in growing children. However, it has not been investigated if whether normal blood pressure percentile values depend on age independent of height. In other words, once height is taken into consideration, do we really need to consider age, another continuous variable, for assessing blood pressure in children? The answer to this question is critical for simplifying the diagnosis procedure and useful for addressing the issue of the current low diagnosis rate of hypertension in pediatric population. Therefore, the objective of this study was to investigate if children of different ages have similar blood pressure levels given that they have an identical height distribution. Using the conventional regression approach to answer this question is challenging because of the difficulties of describing the nonlinear relationships of blood pressure with both height and age. ${ }^{9}$ We adopted a matching 
technique to select a subsample of children aged 7 , 8,9 and 10 years from a large population-based survey in China. By individually matching children according to height, we forced children of different ages to have an identical height distribution. The effect of age on blood pressure was assessed by comparing systolic and diastolic blood pressure levels among four matched groups.

\section{Methods}

Participants and matching

The 2005 Chinese National Surveys on Students' Constitution and Health included a nationally representative sample of over 200000 children aged 7 to 18 years from 1320 schools in China. ${ }^{13,14}$ Those aged $7,8,9$ and 10 years were included in the present study. Each participant in the 10-year-old group was taken as a potential index subject and was individually matched to one participant in the 7-year-old group according to the following criteria: (1) with the same gender, (2) from the same geographic region and (3) with the same or closest height within $\pm 1.0 \mathrm{~cm}$. Each of the matched pairs was further matched to one participant in each of the 8- and 9-year-old groups, according to the same matching criteria. We matched 2539 children (1393 boys and 1146 girls) from each of the four groups. The total number of the matched children in this study was 10156 . To minimize potential selection bias due to the researcher's subjective decision of choosing matching individuals, we developed a computer program for searching and matching children of different ages. If multiple subjects with the same height in a given age group existed in the database, only one child was randomly selected.

\section{Height measurements}

Height $(\mathrm{cm})$ was measured using the same type of portable stadiometer and following a standardized procedure in all survey sites in the country. ${ }^{13,15}$ Subjects were required to wear only light clothes and stand straight, barefoot and at ease when being measured. Height was measured to the nearest $0.1 \mathrm{~cm}$ with a stadiometer, which had been calibrated before use. All measurements were conducted by a team of technicians in each administrative district. All the technicians were required to pass a training course for anthropometric measurements.

\section{Blood pressure measurements}

All blood pressure readings were obtained at a single examination visit according to a standard protocol. As recommended by the National High Blood Pressure Education Program Working Group on High Blood Pressure in Children and Adolescents, ${ }^{8}$ blood pressure readings by an auscultation method with a standardized clinical sphygmomanometer were used in the survey. A stethoscope was placed over the brachial artery pulse, proximal and medial to the cubital fossa and below the bottom edge of the cuff. Cuff bladders with different dimensions $(7,9$, and $12 \mathrm{~cm})$ for children were available in the survey sites. An appropriate cuff bladder width was chosen. The participants were asked to rest in sitting position for $10 \mathrm{~min}$ before the measurement. Systolic blood pressure was determined by the onset of the 'tapping' Korotkoff sounds (K1) and diastolic blood pressure as the fifth Korotkoff sound (K5) or the disappearance of Korotkoff sounds.

\section{Statistical analysis}

Before matching, the means and standard deviations of systolic and diastolic blood pressures were calculated for all age groups in each gender. The one-way analysis of variance was used to test the differences in blood pressure mean values among four age groups. After matching by height, sex and geographic region, we recalculated means and standard deviation of blood pressures of four age groups. As blood pressure values were correlated within matched sets (clusters), we used a randomeffects model for panel data to test the differences of blood pressure levels among four matched groups. The nature of matching was taken into consideration by specifying that the standard errors allow for intracluster correlation. ${ }^{16}$ Kernel density estimates were calculated and plotted to describe the distributions of height in different groups before matching. All analyses were conducted using Stata $11 .{ }^{17}$ We also presented means and 95\% confidence intervals of systolic and diastolic blood pressure values graphically before and after matching.

\section{Results}

Figure 1 shows the height distributions of 7, 8, 9 and 10 year-old boys in the original survey sample. The mean height increased with increasing age from $124.1 \mathrm{~cm}$ in 7 years to 139.3 in 10 years for boys and from $122.6 \mathrm{~cm}$ in 7 years to 139.8 in 10 years for girls (Table 1). As shown in the shaded area in Figure 1, only a small proportion of children were matchable with similar height in all four age groups. We matched 1393 boys and 1146 girls from each of the four age groups by height, sex and geographic region. Therefore, our final analysis included 10156 children ( 5572 boys and 4584 girls). After matching, the four age groups had similar means and standard deviations of height (Table 2).

Both systolic and diastolic blood pressure increased rapidly and significantly over age before matching. Systolic blood pressure increased from $94.4 \mathrm{~mm} \mathrm{Hg}$ in age 7 group to $99.9 \mathrm{~mm} \mathrm{Hg}$ in age 10 for boys and from $92.8 \mathrm{~mm} \mathrm{Hg}$ in age 7 to $98.8 \mathrm{~mm} \mathrm{Hg}$ in age 10 for girls. Diastolic blood pressure increased from $57.5 \mathrm{~mm} \mathrm{Hg}$ in age 7 to 

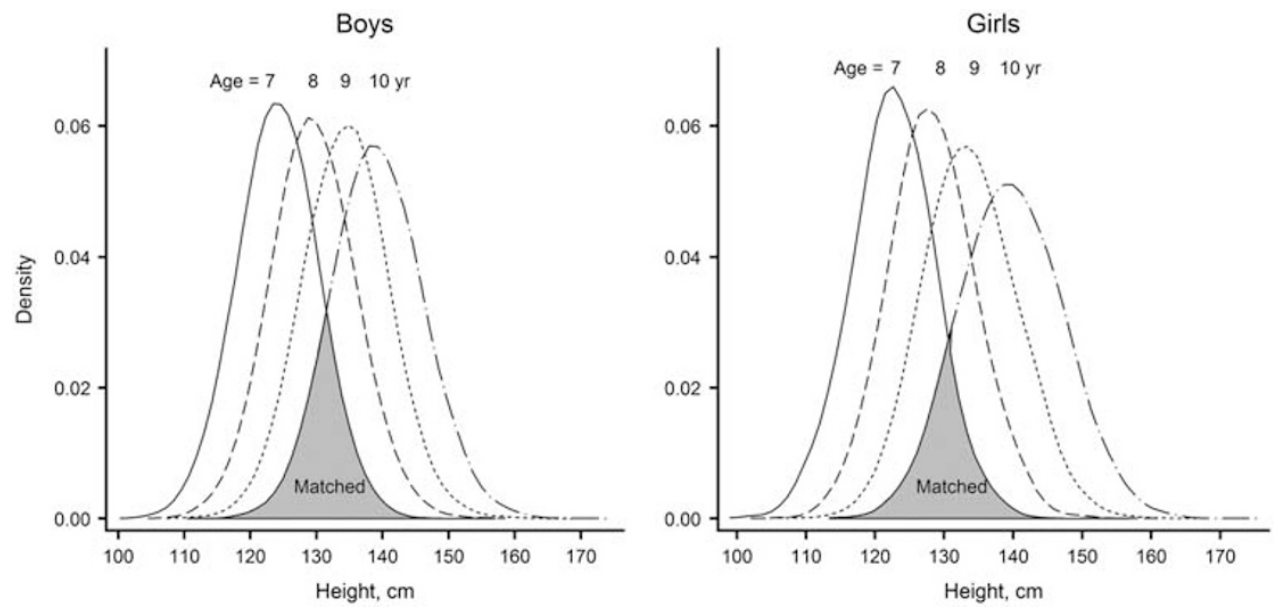

Figure 1 Height distributions by age and sex in Chinese children.

Table 1 Height, systolic and diastolic blood pressure in Chinese children before matching

\begin{tabular}{|c|c|c|c|c|c|}
\hline & \multicolumn{4}{|c|}{ Age, years } & \multirow[t]{2}{*}{$\mathrm{P}$} \\
\hline & 7 & 8 & 9 & 10 & \\
\hline \multicolumn{6}{|l|}{ Boys } \\
\hline Number & 9628 & 9675 & 9712 & 9827 & \\
\hline Systolic BP, mm Hg & $94.4(10.3)$ & $96.0(10.3)$ & $97.8(10.4)$ & $99.9(10.7)$ & $<0.001$ \\
\hline Diastolic BP, mmHg & $57.5(9.7)$ & $58.9(9.6)$ & $60.5(9.7)$ & $62.0(9.5)$ & $<0.001$ \\
\hline Height, cm & $124.1(6.1)$ & $129.5(6.4)$ & $134.4(6.5)$ & $139.3(6.9)$ & $<0.001$ \\
\hline \multicolumn{6}{|l|}{ Girls } \\
\hline Number & 9560 & 9555 & 9597 & 9726 & \\
\hline Systolic BP, mm Hg & $92.8(10.1)$ & $94.2(10.2)$ & $96.4(10.5)$ & $98.8(10.7)$ & $<0.001$ \\
\hline Diastolic BP, mm Hg & $57.0(9.5)$ & $58.3(9.6)$ & $59.8(9.6)$ & $61.5(9.6)$ & $<0.001$ \\
\hline Height, cm & $122.6(6.0)$ & $128.3(6.3)$ & $133.8(6.9)$ & $139.8(7.5)$ & $<0.001$ \\
\hline
\end{tabular}

Abbreviation: BP, blood pressure.

Table 2 Height, systolic and diastolic blood pressure in Chinese children aged 7 to 9 years after individually matched by height

\begin{tabular}{|c|c|c|c|c|c|}
\hline & \multicolumn{4}{|c|}{ Age, Years } & \multirow[t]{2}{*}{$\mathrm{P}$} \\
\hline & 7 & 8 & 9 & 10 & \\
\hline \multicolumn{6}{|l|}{ Boys } \\
\hline Number & 1393 & 1393 & 1393 & 1393 & \\
\hline Systolic BP, mm Hg & $97.5(10.5)$ & $96.9(10.0)$ & $96.9(9.7)$ & $97.3(9.8)$ & 0.26 \\
\hline Diastolic BP, mm Hg & $60.1(9.7)$ & $59.7(9.6)$ & $60.2(9.2)$ & $60.2(9.0)$ & 0.47 \\
\hline Height, cm & $131.5(4.4)$ & $131.5(4.4)$ & $131.5(4.4)$ & $131.5(4.4)$ & 0.92 \\
\hline \multicolumn{6}{|l|}{ Girls } \\
\hline Number & 1146 & 1146 & 1146 & 1146 & \\
\hline Systolic BP, mm Hg & $94.9(10.3)$ & $94.7(10.0)$ & $94.9(9.9)$ & $95.2(9.5)$ & 0.73 \\
\hline Diastolic BP, mm Hg & $58.5(9.3)$ & $58.8(9.3)$ & $59.0(8.9)$ & $59.1(9.2)$ & 0.40 \\
\hline Height, cm & $130.3(4.4)$ & $130.3(4.4)$ & $130.3(4.4)$ & $130.3(4.4)$ & 0.95 \\
\hline
\end{tabular}

Abbreviation: BP, blood pressure.

$62.0 \mathrm{~mm} \mathrm{Hg}$ in age 10 for boys and from $57.0 \mathrm{~mm} \mathrm{Hg}$ in age 7 to $61.5 \mathrm{~mm} \mathrm{Hg}$ in age 10 for girls (Table 2).

After matching by height, sex and geographic region, the trend of a sharp increase in systolic and diastolic blood pressure levels over age disappeared (Figure 2). Both systolic and diastolic blood pressure levels were quite similar among the four age groups.
The differences among the four groups were not statistically significant for both boys and girls in both systolic and diastolic blood pressure values (Table 2). The absolute differences among the four groups are small and not statistically significant. The maximum difference in diastolic blood pressure was observed between 7 and 10 year-old girls, 

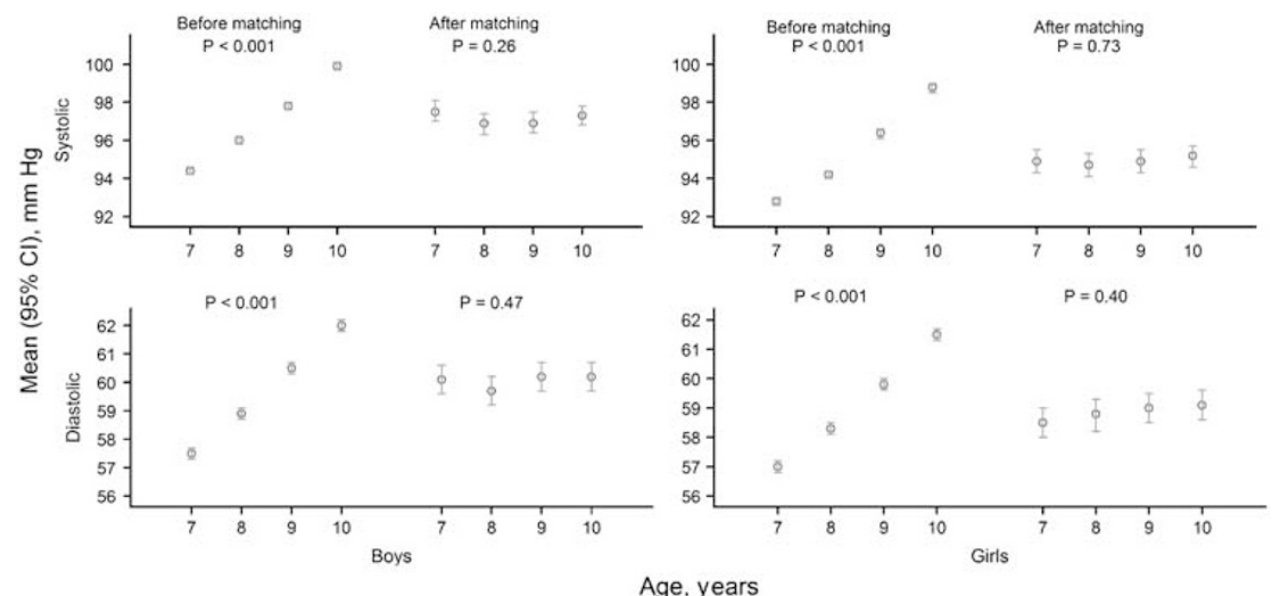

Figure 2 Systolic and diastolic blood pressure levels before and after matching by height in Chinese children.

which was only $0.6 \mathrm{~mm} \mathrm{Hg}(95 \%$ confidence interval: $-0.1,1.3)$. The maximum difference in systolic blood pressure was also only $0.6 \mathrm{~mm} \mathrm{Hg}(95 \%$ confidence interval: $-1.3,0.1)$ observed between 7 and 8 year-old boys.

\section{Discussion}

Recent guidelines published in the Forth Report on the Diagnosis, Evaluation, and Treatment of High Blood Pressure in Children and Adolescents provide standard blood pressure percentiles by sex, year of age and height percentile. ${ }^{8}$ Using those blood pressure percentiles to determine if a child has an elevated blood pressure is a complicated procedure, which was considered accountable for the underdiagnosis of hypertension in children. ${ }^{7}$ The development of such norms depending on two continuous variables (age and height) is also challenging because of the nonlinear relationships of blood pressure levels with age and height. ${ }^{9}$ In this study, we found that children of different ages with an identical height distribution have similar blood pressure levels. Age has little impact on blood pressure values once the impact of height is taken into consideration. This phenomenon exists in both boys and girls for both systolic and diastolic blood pressure measurements. Our findings suggest that children with the same height tend to have similar normal blood pressure values regardless of their ages. Therefore, the current guidelines for assessing blood pressure according to age and height in children may be unnecessarily complicated. The process of assessing blood pressure in children should be substantially simplified, at least for children aged from 7 to 10 years. Our data support that it is sufficient to construct normal blood pressure percentiles as a function of height alone rather than a function of both age and height. Simplifying the diagnosis procedure can be helpful for addressing the issue of the current low diagnosis rate of hypertension in children.

The normal blood pressure values in children in early guidelines were constructed as age and sex specific percentiles. ${ }^{18,19}$ Because body size is the most important determinant of blood pressure in children, the recent guidelines provided age, sex and height specific percentiles of systolic and diastolic blood pressures. ${ }^{8,20}$ As those normal blood pressure percentile values depend on two continuous variables, it is complex and time consuming to determine if a child has an elevated blood pressure in health care settings. The original justification for this approach is that for a given age, blood pressure levels are higher in larger children and body size needs to be accounted for. ${ }^{12}$ However, no studies have assessed if age is a necessary determinant once height is accounted for. Our study is perhaps the first effort to examine if age is associated with blood pressure independent of height.

There are several strengths in this study. We took the challenge to individually match 2539 sets of four different age groups, with a total of 10156 Chinese children. The large population-based survey data in China made the matching of such a large number of children of different ages by height possible. Matching is an intuitively straightforward approach to control for the effect of height on blood pressure values. This approach overcomes the difficulty of determining the nonlinear relationship between blood pressure and height when using a regression method.,10 Matching four groups is also a time consuming procedure and with the application of a computer program developed by our team, we were able to match such a large number of children of different ages. The large sample size in our study resulted in a high statistical power, as reflected by the narrow confidence intervals of differences between the groups with the maximum and minimum blood pressure values. One potential limitation of our study is that we only compared the blood 
pressure levels among 7, 8, 9 and 10 year-old groups. As the age range in our study was relatively small from 7 to 10 years, whether our findings apply to children beyond the observed age range needs to be further assessed. The study sample was from a homogenous population of Chinese children whose height distribution may be different from those in other racial and ethnic groups. Therefore, further studies are also needed to investigate if the phenomenon that we observed in Chinese children applies to children in other populations.

\section{Conclusions}

Blood pressure values differ little over ages from 7 to 10 years given they have an identical height distribution. Therefore, our findings, if confirmed in other age groups and in other populations, suggest that only height needs to be considered for establishing blood pressure normal percentiles for each gender in children. The diagnosis procedure of elevated blood pressure for children in the current consensus guidelines can and should be considerably simplified.

What is known about this topic

- Normal blood pressure in children is currently defined as a function of two continuous variables, age and height.

What this study adds

- Children with a same height have similar normal blood pressure values regardless of their age.

- Current guidelines for assessing blood pressure according to age and height in children may be unnecessarily complicated.

- It may be sufficient to construct normal blood pressure percentiles as a function of height alone rather than a function of both age and height.

\section{Conflict of interest}

The authors declare no conflict of interest.

\section{Acknowledgements}

The data analysis of this study was supported by a grant from the National Health and Medical Research Council of Australia (NHMRC, 511013) to ZW. We thank the members of the Chinese National Survey on Students' Constitution and Health for providing access to the survey data.

\section{References}

1 Ogden CL, Carroll MD, Curtin LR, McDowell MA, Tabak CJ, Flegal KM. Prevalence of overweight and obesity in the United States, 1999-2004. JAMA 2006; 295(13): 1549-1555.

2 Strauss RS, Pollack HA. Epidemic increase in childhood overweight, 1986-1998. JAMA 2001; 286(22): 2845-2848.

$3 \mathrm{Wu}$ Y. Overweight and obesity in China. BMJ 2006; 333(7564): 362-363.

4 Ji CY, Cheng TO. Epidemic increase in overweight and obesity in Chinese children from 1985 to 2005. Int J Cardiol 2009; 132(1): 1-10.

5 Ostchega Y, Carroll M, Prineas RJ, McDowell MA, Louis T, Tilert T. Trends of elevated blood pressure among children and adolescents: data from the National Health and Nutrition Examination Survey 1988-2006. Am J Hypertens 2009; 22(1): 59-67.

6 Must A, Spadano J, Coakley EH, Field AE, Colditz G, Dietz WH. The disease burden associated with overweight and obesity. JAMA 1999; 282(16): 1523-1529.

7 Hansen ML, Gunn PW, Kaelber DC. Underdiagnosis of hypertension in children and adolescents. JAMA 2007; 298(8): 874-879.

8 National High Blood Pressure Education Program Working Group on High Blood Pressure in Children and Adolescents. The fourth report on the diagnosis, evaluation, and treatment of high blood pressure in children and adolescents. Pediatrics 2004; 114(2): 4th report, 555-576.

9 Rosner B, Cook N, Portman R, Daniels S, Falkner B. Determination of blood pressure percentiles in normalweight children: some methodological issues. Am J Epidemiol 2008; 167(6): 653-666.

10 Rosner B, Cook N, Portman R, Daniels S, Falkner B. Blood pressure differences by ethnic group among United States children and adolescents. Hypertension 2009; 54(3): 502-508.

11 Gillum RF, Prineas RJ, Horibe H. Maturation vs age: assessing blood pressure by height. J Natl Med AssoC 1982; 74(1): 43-46.

12 Rosner B, Prineas RJ, Loggie JM, Daniels SR. Blood pressure nomograms for children and adolescents, by height, sex, and age, in the United States. $J$ Pediatr 1993; 123(6): 871-886.

13 Chinese Students' Physical Fitness and Health Research Group. Reports on the physical fitness and health research of Chinese school students. Higher Education Press: Beijing, 2008.

14 Ji CY, Cheng TO. Prevalence and geographic distribution of childhood obesity in China in 2005. Int $J$ Cardiol 2008; 131(1): 1-8.

15 Cameron N. The methods of axiological anthropometry. In: Falkner FT, Tanner JM (eds). Human growth. Plenum Press: New York, 1978.

16 Babe-Hesketh S, Skrondal A. Multilevel and Longitudinal Modeling Using Stata, 2nd edn Stata Corp LP: College Station, Texax, 2008.

17 StataCorp. Stata Statistical Software: Release 11. StataCorp LP: College Station, Texas, 2009.

18 Blumenthal S, Epps RP, Heavenrich R, Lauer RM, Lieberman E, Mirkin B et al. Report of the task force on blood pressure control in children. Pediatrics 1977; 59(5 2 suppl): I-II, 797-82.

19 National Heart, Lung, and Blood Institute, Bethesda, Maryland. Report of the Second Task Force on blood pressure control in children 1987. Task force on blood pressure control in children. National Heart, Lung, and 
Blood Institute, Bethesda, Maryland. Pediatrics 1987; 79(1): 1-25.

20 National High Blood Pressure Education Program Working Group on Hypertension Control in Children and Adolescents. Update on the 1987 Task Force report on high blood pressure in children and adolescents: a working group report from the National High Blood Pressure Education Program. National High Blood Pressure Education Program Working
Group on Hypertension Control in Children and Adolescents. Pediatrics 1996; 98(4 Part 1): 649-658.

This work is licensed under the Creative Commons Attribution-NonCommercialNo Derivative Works 3.0 Unported License. To view a copy of this license, visit http://creativecommons. org/licenses/by-nc-nd/3.0/ 